\title{
The Study of Productivity Differences between Female and Male Researcher: Case Studies in Indonesian R \& D Institutions
}

\author{
Nany Grace B. Simamora, Indri Juwita Asmara, and Elmi Achelia
}

\begin{abstract}
This paper reviews gender issues in their productivity as researchers. By collecting researcher data from Indonesian $R \& D$ institution and the output they have produced (from google scholar), this paper explores the determinants of research productivity with evaluated scientific paper, citations, and h-index. In order to find out whether there is any significant difference between male and female productivity distributions or the issue of the gender gap, a Kruskal-Wallis test is used. By studying based on level of education and scientific fields, this paper finds that even though in terms of numbers, male researchers are still more than women, but when stratified by both academic degree and study field, there was enough evidence to conclude that no significant differences between publication productivity for men and women
\end{abstract}

Index Terms-Female, gender, male, researcher, research productivity.

\section{INTRODUCTION}

Indonesia is a developing country which has now become 10 countries with strong economies [1]. Referring to India, and China as a newly developed country, Indonesia seeks to improve science and technology and innovation. Therefore, Indonesia is increasing $\mathrm{R} \& \mathrm{D}$ activities, as well as strengthening resources through $R \& D$ budgets, $R \& D$ human resources and infrastructure. Basically, $R \& D$ institutions in Indonesia are in four sectors, namely the government sector, higher education, private or industrial and non-profit institutions. Among the four sectors, the highest number of researchers is the higher education (63\% of total researchers), then government (24\%) and private or industrial (10\%) [2]. However, government $\mathrm{R} \& \mathrm{D}$ institutions dominate $\mathrm{R} \& \mathrm{D}$ activities in Indonesia. Around $82 \%$ of national R\&D expenditure comes from the government. This is because government $R \& D$ institutions produce strategic things that are more in the public interest, so that institutional capacity is very important to develop [3]. The quality of $R \& D$ is measured through technological productivity produced by the institution per unit of resources and / or costs managed. Whereas dissemination capacity is measured by the intensity

Manuscript received January 16, 2019; revised April 12, 2019. This work was supported in part by Research Center of Policy and Management Science and Technology, Indonesian Institute of Sciences and Directorate General of Research and Development Strengthening- Ministry of Research Technology and Higher Education.

The authors are with Research Center of Policy and Management Science and Technology, Indonesian Institute of Sciences, Indonesia (e-mail: nani002@lipi.go.id,_grcsimamora@gmail.com, indri003@lipi.go,id, indriasmara@gmail.com, elmi001@lipi.go.id, elmiachelia@gmail.com). and range of publication of research activities carried out and science and technology produced through both print and electronic media, the quantity and quality of science and technology adopted by the users, and royalties received by the top institutions [4]. In this case the management of R\&D institutions managing Human Resources including researchers becomes important.

Measuring the capacity and capability of researchers in R\&D institution are different from other institutions or organizations. Researchers are relating to the R\&D dimensions, namely R\&D in higher education institutions, government or private. The number of researchers reflect the institutional capacity including creating and applying new knowledge. Institutional performance is determined by the magnitude of the potential to create, introduce and disseminate technological innovation and its use to the community [5]. In other words, it is not just the amount but also calculates the skill level based on the proportion of the total workforce. To obtain researchers that has great performance, a good management is needed. Human Resources Development (HRD) has a role in planning, developing and managing individuals and groups in $R \& D$ structures and organizations. Basically, HRD is complex, diverse and interdependent. The thing that distinguishes between HRD in R\&D institutions and other institution is the personnel. R\&D personnel are educated, skilled and professional. Researchers tend to be professionally oriented, while personal in non- $R$ \& $\mathrm{D}$ institutions tend to be institutional oriented [3].

Basically the popularity of $R \& D$ institutions is highly dependent on researchers and scientists working in it who can build institutional images, expand networks, raising funds from research donors to competition between institutions which are then measured in the index. Researchers who have the potential, expertise, skills or expertise in creating, developing and utilizing science and technology as well as credibility in the scientific community are valuable assets for the institution. This situation makes scientific productivity a measure of the career success of researchers. Researchers productive are given the rewards with promotions and lucrative job mobility. But researchers who are unproductive, then considered unsuccessful. They are sometimes directed to leave the institution. The level of scientific publications then becomes an accurate measure of productivity [6].

Furthermore there are other issues in the productivity of researchers, especially between female and male researchers. Based on 50 empirical studies since 1920, female scientists produced less than half of the scientific writings compared to male colleagues [7]. This is believed to always be consistent 
from year to year which then causes confusion [7]. Therefore a re-study was conducted by analyzing male and female scientists who received doctoral degrees in 1969-1970 and analyzed their productivity during the first 12 years of their careers. The result is almost the same. Women still give less than half, although their numbers increase. Other researchers conducted a study based on empirical evidence in 1969, 1973, 1988 and 1993 which later found that the gap in scientific productivity between women and men was getting smaller and smaller and that happened when female scientists were placed in a secular environment [6]. Studies on young researchers also show that their productivity is increasing every year compared to senior researchers. A more competitive scientific system allows this to happen. However, even the most productive female researchers still cannot outperform their male counterparts [8]. Research on the relationship between gender and scientific productivity has not been done much in Indonesia. This knowledge is important because based on The National Training Educational Center for Research Development - LIPI 2018 data, for the past five years there has been an increase in the number of female researchers in government $R$ \& $D$ institutions, which averages $7 \%$ annually. Even in 2018, the number of young female researchers (aged 25-29 years) slightly exceeds men. For this reason, it is necessary to know the productivity of female researchers, whether there is a difference in productivity between female researchers and male colleagues. Although the study of women as scientists (chapter II) shows exist of obstacles and deep in their career. In the end this knowledge has become important for HR decision makers to wisely manage researchers so that $\mathrm{R} \& \mathrm{D}$ institutions get maximum profits. Therefore, this paper describes the results of the analysis of differences in scientific productivity between female and male researchers based on the level of education by measuring scientific publications indexed by Google Scholar, citations, h-index.

Thus, the systematics of this paper is as follows Chapter 1 explains the purpose of this paper, namely to examine the existence of scientific productivity differences between female scientists and male partners, then in Chapter II describes about women as scientists. The next section, we will discuss methodology. Chapter 4 explains the profiles of researchers in the Indonesian government R \& D institutions. Chapter 5 we will discuss the results of the analysis. Chapter 6 we finally give some conclusions.

\section{WOMEN AS SCIENTISTS}

Early 20th century female scientists such as Rosalind Elsie Franklin (1920-1958) were pioneers of Molecular Biology, Maria Goeppert-Mayer (1906-1972) Nobel laureates in Physics, or Helen Sawyer Hogg (1905-1993) who were astronomical scientists depicting real life about women who survived as researchers [9]. Those with various obstacles have participated in revealing the secrets of nature since the beginning of civilization. For them the existence or recognition of achievement is the most important compared to the number. With unique and different levels, all female scientists face obstacles when their scientific work is published simply because they are female [9]. Many of the female scientists were not allowed to get further education; only a few people allowed to work but without payment. Privileges are only given to men with the same job. Then some female scientists along with male colleagues fought against fascism, racism, and discrimination based on class and ethnicity [8].

What about the current conditions? In the past decade the gender gap in labor force participation as researchers has in many cases been wider than the gender gap in the educational trajectory. This evidenced of research that shows that scientists and engineers in Latin America face more significant barriers than men with the same education [10]. The development of women's careers as scientists is always characterized by two things: first related to the high level of resignation for women who experience negative things after entering a male-dominated field and the second is referring to the difficulties and obstacles of women to climb career paths [11]. Women concentrate at the bottom of the hierarchy, and are not present in positions, decision-making or leadership.

A full understanding of the factors that hinder the career path of female scientists is that there are still a number of myths which later become stereotypes and ambivalence for women who have a career as scientists. These supervisors include [11]: a. Women do not have the ability and encouragement to succeed; b. The problem of women's representation naturally can be solved with the passage of time; c. Changing election rules and promotions that encourage gender equality has a negative impact on standards of excellence and progress; d. Female scientists are less productive than male counterparts; e. Female scientists are not as competitive as men; f. Female scientists are a bad investment because they are more interested in and spend more time on family and children; g. Conventional systems have worked well in producing knowledge.

\section{Methodology AND BASIC CONCEPT}

This study uses the concepts and definitions of research activities and researchers as follows: R\&D activities that aim to achieve either specific or general objectives, even if these carried out by different performers. To perform an activity become an R\&D activity, it must satisfy 5 core criteria. The activity must be: $\bullet$ novel $\bullet$ creative $\bullet$ uncertain $\bullet$ systematic - transferable and/or reproducible [4]. Researcher is the people who perform $R \& D$, the highly trained scientists and engineers.

To measure productivity, this study uses three parameters namely scientific publications, citations, and h-indexes produced by researchers working in the Indonesian government $\mathrm{R} \& \mathrm{D}$ institutions. Written scientific publications reported that describe the results of original research and then published [12]. Scientific publications must meet certain requirements about how this paper written and how it published. The process towards publication is as important as the content, style and organization of published papers. According to this view, scientific papers must be valid publications, i.e. they must be published in the right place, such as in peer reviewed journals or in top-ranked conferences [12].

Citation is a brief reference to the source that directs the reader to the full reference at the end of scientific work updates [13]. More scientific writings cited by other 
researchers mean that scientific writings are increasingly spread out and become a measure for researchers. The quote will be related to h-index [13].

In 2005 Jorge Hirsch developed the $\mathrm{H}$-index. $\mathrm{H}$-index is a single number indicator to evaluate the scientific achievement of a researcher. The simple way of calculating is as follows: "A scientist has an index $\mathrm{h}$ if $\mathrm{h}$ of the paper $\mathrm{Np}$ each has at least a quote, and another paper $(\mathrm{Np}-\mathrm{h})$ each has fewer than $\leqq h$ quotations each" [14]. Measuring the $\mathrm{H}$-index gives an advantage in evaluating a scientific paper through integration between productivity (number of publications per total scientist) and the impact (impact of peer scientists' papers) on one indicator [14].

Data collected is obtained from the National Training Educational Center for Research Development - LIPI (Pusbindiklat - LIPI) database including the name of the researcher, employee identification number, academic degree and field of science. Scientific, citation and h-index publications taken from the google scholar through Harzing.com. Google scholar is an internet-based search engine designed to search for scientific information, including peer-reviewed articles, theses, books, preprints, abstracts, and court opinions from academic publishers, professional societies, online repositories, universities, and other Web sites [15] .

To analyze productivity differences between female and male researchers, this study used the Kruskal-Wallis Test method [16]. In statistical analysis, sometimes it is advantageous to use ranks instead of the original observations-that is, to sort the $\mathrm{N}$ observations by value and replace the smallest by 1 , the second smallest by 2 , and so on, the largest being replaced by N. The advantages are (1) Easy to calculate; (2) Only very general assumptions made about the kind of distributions from which the observations come; (3) Rank test have a better chance than usual test procedure to detecting kinds of difference of real interest, when the assumptions are too far from reality.

Kruskal-Wallis test or Kruskal-Wallis test by ranks or one-way ANOVA on ranks is a non-parametric method for testing some samples whether come from same distribution. Since it is a nonparametric method, Kruskal-Wallis test does not assume normal distribution of residuals, unlike analogous one-way ANOVA.

The hypothesis of Kruskal-Wallis test is

$H_{0}=$ Median of all groups is equal

$H_{1}=$ At least one median is different

The test statistics to be computed if there no ties (if no two observations are equal) is

where

$$
H=\frac{12}{N(N+1)} \sum_{i=1}^{C} \frac{R_{i}^{2}}{n_{i}}-3(N+1)
$$

$N=\sum n_{i}$, the number of observations in all samples combined,

$n_{i}$, the number of observations in $i$ th sample,

$R_{i}$, the sum of the ranks in $i$ th sample,

$C$, the number of samples.

When significance level $\alpha$ is used, $H$ is distributed as $\chi_{\alpha}^{2}(C-1)$ and $p_{\text {value }}$ calculated as

$$
\operatorname{Pr}\left[\chi_{\alpha}^{2}(C-1) \geq H\right]=p_{\text {value }}
$$

And, when $p_{\text {value }}<\alpha, H_{0}$ is rejected, and conclude that at least one median is different.

If there are ties, each observation is given the mean of the ranks for which it is tied and adjusted test statistics is,

$$
H_{a d j}=\frac{H}{1-\frac{\sum T}{N^{3}-N}}
$$

where $T=(t-1) t(t+1)=t^{3}-t$ for each group of ties, $\mathrm{t}$ being the number of tied observations in the group.

When significance level $\alpha$ is used, $H_{a d j}$ is distributed as

$\chi_{\alpha}^{2}(C-1)$ and $p_{\text {value }}$ calculated as

$$
\operatorname{Pr}\left[\chi_{\alpha}^{2}(C-1) \geq H_{a d j}\right]=p_{\text {value }}
$$

and, when $p_{\text {value }}<\alpha, H_{0}$ is rejected, and conclude that at least one median is different

\section{PROFILE RESEARCHERS IN R\&D GOVERNMENT}

Indonesia has a policy regarding the existence of researchers working in government. Each researcher is required to enter the structure of the research position. There are four functional levels of researcher starting from the lowest are: first researcher level, young researcher level, middle researcher level and principal researcher level. At each level, researchers are trained in an education and training agency. Furthermore, for assessments at every level, researcher who are required to fulfill the requirements for increasing levels such as publishing their research results into national and international journals, or registering for patents, etc.

To give an idea of the condition of researchers working in the government sector, below is described the proportion of Indonesian researchers based on gender, age, education level and research position.

In 2018, the proportion of female and male researchers is as shown in Fig. 1. Researchers proportion of women and men are fairly balanced.

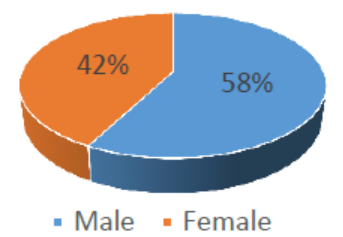

Fig. 1. Proportion of female and male researchers, 2018. Source: Processed from pusbindiklat LIPI, 2018

This balanced proportion has occurred since 2010-2018 with a tendency to increase the proportion of female researchers every year (Fig. 2.).

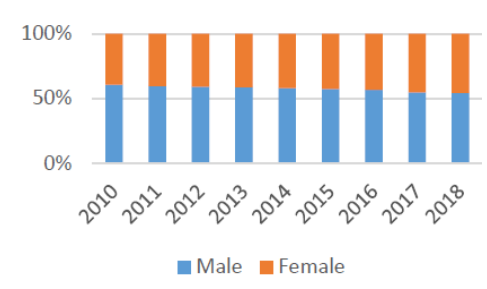

Fig. 2. Trend of proportion of female and male researchers, 2010-2018. Source: processed from pusbindiklat LIPI, 2018 
Describe researchers' age shows a pattern of distribution that is not too different between male and female researchers. The highest proportion of researchers in productive age is between the ages of 30-39 years (Fig. 3).

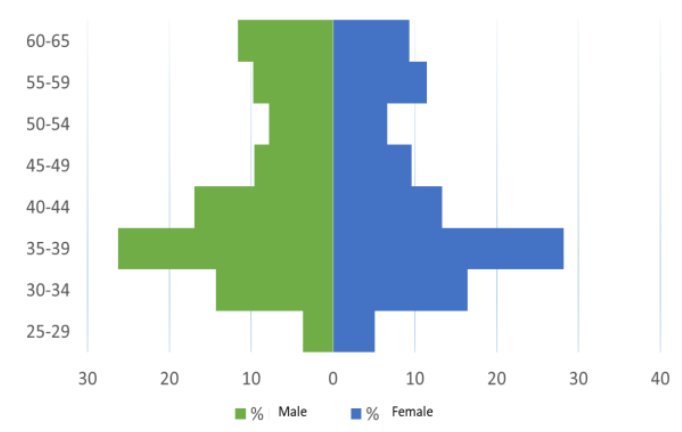

Fig 3. proportion of female and male researchers based on age. Source: processed from pusbindiklat LIPI, 2018

Based on the level of education, there is no significant difference between the proportion of women and men. This means that there is a gender balance at academic degree (Fig. 4).

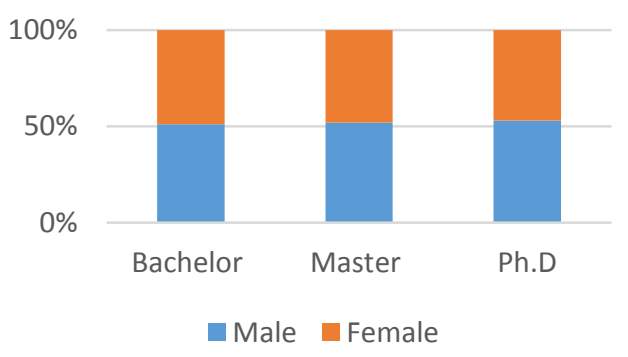

Fig. 4. proportion of female and male researchers based on academic degree.

Source: Processed from pusbindiklat LIPI, 2018.

A different picture when viewed from the position structure of the researcher. When viewed from the level of researchers, the higher the level of researchers, the fewer women in it. The most female researchers at the first and second levels (Fig. 5)

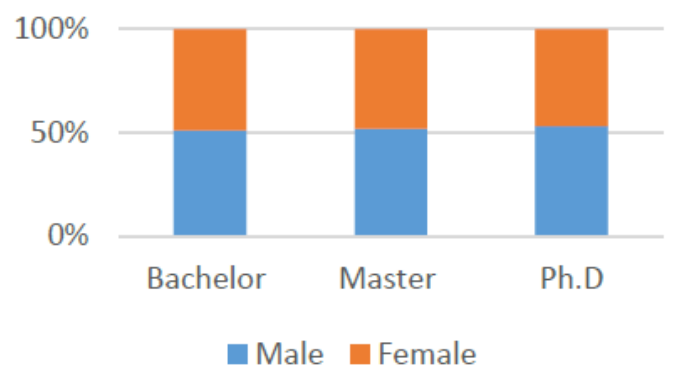

Fig. 5. Proportion of female and male researchers based on researcher's position level.

Source: processed from pusbindiklat LIPI, 2018

Many female researchers entered the first and second position in the range of 26-45 years. I.e. the 46-50 year thereafter, they started higher positions. Female researchers also managed to reach the highest level, as a principal investigator at that age (although fewer than 10 people) (Fig. 6)

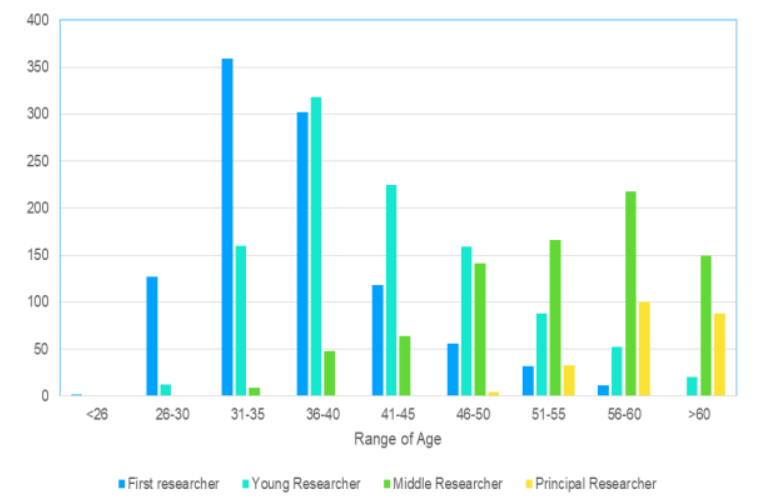

Fig. 6. Distribution of female researchers based on research positions and age.

Source: processed from pusbindiklat LIPI, 2018

A slightly different pattern seen in male researchers. There is a shift in age (early age) in higher career achievement in research positions. Initially, male researchers arranged their careers at the age of 26-30, but there were a number of male researchers who could occupy the position of intermediate researchers at the age of 31-35, even the main research position was over 41-46 (Fig. 7).

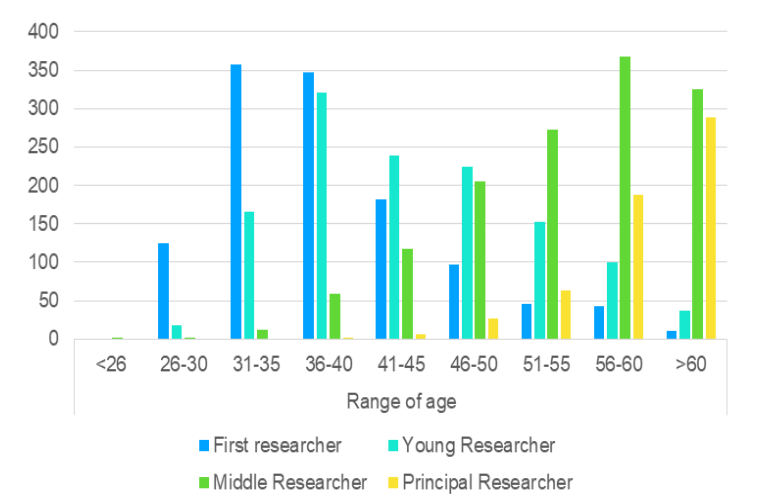

Fig. 7. Distribution of male researchers based on research positions and age.

Source: processed from pusbindiklat LIPI, 2018.

\section{SCIENTIFIC PRODUCTIVITY ANALYSIS BASED ON GENDER}

In the last chapter, it is known that the profile of researchers in government $\mathrm{R} \& \mathrm{D}$ institutions, especially female researchers, which in number and proportion based on academic level is not too different from male counterparts, but from the level of position there are significant differences, then this chapter describes differences their scientific productivity.

An analysis of productivity differences between female and male researchers is shown in terms of publishing scientific papers. Furthermore, the differences in the quality of the research produced are proven through citation and h-index sizes.

This study uses the Kruskal-Wallis method with statistical analysis described as follows. It previously explained that the data has a median value. Median is preferred to mean when there are few extremes scored in the distribution [17]. Median also not distorted by outliers or skewed data [17]. As shown on histogram, total number of paper publications, number of citations, h-index and career duration are skewed data. So, 
median will be used to represent data.

A nonparametric analysis, Kruskal-Wallis Test was performed to calculate difference between median for total number of paper publications, number of citations, h-index, and career duration. Data stratified by gender, and academic degree. All statistical analyses were performed using Minitab (see figure 8.).
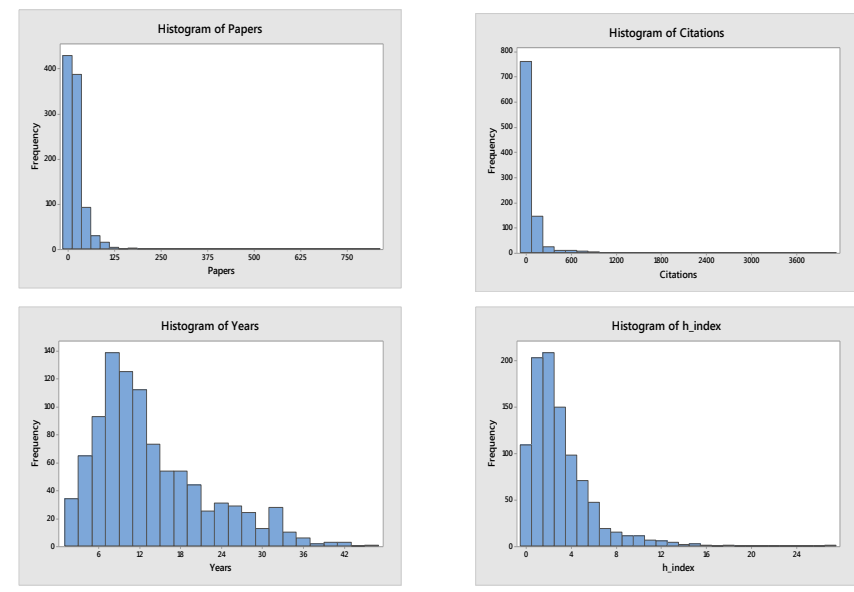

Fig. 8. the calculate difference between median for total number of paper publications, number of citations, h-index, and career duration.

\section{A. Number of Paper Publications}

In general, men had a higher median number of paper publications $(P=0.002)$ than women. Median number of paper publications was 16 for men and 13 for women.

When stratified by academic degree, there were no significant difference between men and women (bachelor and Ph.D. degree), except for Master degree, men had higher median number of paper publications than women $(P=0.009)$. Median number of paper publication was 15 for men and 12 for women.

When stratified by field of study, there were significant difference between men and women. Among the field of Science, Technology, Engineering, Mathematic (STEM), men had median number of paper publications 16, higher than women $13(P=0.022)$. Among social science, men also had median number of paper publications 19 , higher than women $10(P=0.025)$.

When stratified by both academic degree and field of study, there were no significant difference between men and women, except for Master degree and field of STEM, men had median number of publications 15 , higher than women 12 $(P=0.024)$.

\section{B. Number of Citations}

In general, men had a higher median number of citations $(P=0.046)$ than women. Median number of citations was 19 for men and 16 for women.

When stratified by number of citations, there were no significant differences between median number of citations for men and women.

When stratified by field of study, there were significant difference between men and women, except for field of STEM. Among social science, men had median number of citations 28 , higher than women $5(P=0.007)$.

When stratified by both academic degree and field of study, there were no significant differences between median number of citations for men and women.

\section{H-Index}

In general, there were no significant differences between median h-index for men and women. When stratified by academic degree, there were no significant differences between median h-index for men and women.

When stratified by field of study, there were significant difference between men and women, except for field of STEM. Among social study field, men had median h-index 3, higher than women $1(P=0.003)$.

When stratified by both academic degree and field of study, there were no significant difference between median h-index for men and women.

\section{Career Durations}

In general, there was no significant difference between median career durations for men and women.

When stratified by academic degree, there were no significant differences between median career durations for men and women.

When stratified by study field, there were no significant differences between median career durations for men and women.

When stratified by both academic degree and study field, there were no significant differences between median career durations for men and women.

\section{CONCLUSION}

Currently a career as a researcher is a concern for women. This is because the number of female researchers tends to approach male researchers and continues to increase from year to year. Even at productive age (between 25-35 years), the number of women exceeds men. The number of women with S1, S2 and S3 education levels has also equaled men. This shows the equality of quantity and quality of female and male researchers. It's just a little lame when calculating the proportion of female and male researchers based on research positions. The highest proportion of female researchers at the low level of office is the first level of researchers and the level of young researchers. This proportion decreases with the increase in the level of research.

Analysis of scientific productivity in this case measured by scientific publications indexed by Google Scholar, citations and h-index shows that in general there are significant differences between female and male researchers. In terms of the number of publications, female researchers lag behind men. Significant differences are also seen when analyzed based on education level, especially in master degree. But there was no significant productivity difference for researchers with bachelor degree and $\mathrm{Ph} . \mathrm{D}$. degree. Especially in the field of STEM and social sciences, the scientific productivity of male researchers is superior to women. The more interesting thing is that if analyzed by the level of education and science, there is no significant difference between women and men in publishing the results of their research.

Analysis of citations shows that the productivity of female and male researchers is the same in terms of number of citations. Things that are not different are also shown to 
researchers with STEM. In this case there was no significant difference in productivity between female and male researchers based on their academic degree and field of study.

In the case of h-index female researchers have the same ability as male colleague; because the results of the analysis show that there are no significant differences between female and male researchers based on education level and field of science. Similarly, if studied based on the length of career time. It turned out that there were no significant differences between female and male researchers who were sorted by academic degree and field of science.

The final conclusion is if examined based on education level and scientific field, there are no gender differences that affect scientific productivity.

\section{REFERENCES}

[1] Indonesia Economic Quarterly Learning More, Growing Faster, The world bank, 2018, pp. 2-3.

[2] S\&T in Indonesia- In Brief, Center for Science and Technology Development Studies, Jakarta, 2014, p. 29.

[3] K. Demir. (April 2016). Human Resource Management of Government Defense R\&D, Organizations. Cyber Workforce Issues [Online]. pp. 24-30. Available www.softwaresuccess.org/papers/2016_Demir_Crosstalk_201603. pdf.

[4] K. B. Akhilesh, $R \& D$ Management, New York: Springer, 2014, ch 1, pp. 6-7.

[5] Frascati Manual: Proposed Standard Practice for Surveys on Research and Experimental Development, The Organisation for Economic Co -operation and Development (OECD), Paris, 2015, pp 43-79.

[6] K. A. Shauman and Y. Xie, "Explaining sex differences in publication productivity among postsecondary faculty," Springer Unequal Outcomes. Innovations in Science Education and Technology, vol. 15, 2003.ch.9. pp. 175-183.

[7] J. R. Cole, H. Zuckerman, "The productivity puzzle: Persistence and change in pattern of publication of men and women scientist," $A$ Research Annual Women in Science, vol. 2. J1984. pp. 217-258.

[8] K. Prpiû, "Gender and productivity differentials in science," Budapest Scientometrics, and Kluwer Academic Publishers, vol. 55, no. 1, pp. 27-58. 2002.

[9] M. Maisel and L. Smart. Women in Science. San Diego Supercomputer Center. [Online]. Available: https: //www.sdsc.edu/ScienceWomen/GWIS.pdf

[10] R. Castillo, G. Matteo, and T. Ezequiel, Women in Science and Technology: What does the Literature Say? Inter-American Development Bank. No. IDB-TN-637, pp. 3-29.

[11] S. J. Ceci and W. M. Williams, Why Aren'T more Women in Science? Top Researchers Debate the Evidence, $1^{\text {st }}$. ed. Washington, DC: American Psychological Association, 2007, pp. 34-35.

[12] R. A. Day and B. Gastel, How to Write and Publish a Scientific Paper, $7^{\text {th }}$. ed. Cambridge University Press, 2012, pp. 18-22.

[13] A. Truelove. A Guide to Citing, Referencing and Avoiding Plagiarism. [Online]. Available: http://askfxplus.ac.uk/sites.

[14] M. Huang and P. Chi, "A comparative analysis of the application of $\mathrm{H}$-index, G-index and A-index in institutional-level research evaluation," Journal of Library and Information Studies, vol. 8, no. 2, pp. $1-10,2010$

[15] W. Badke, Google Scholar and the Researcher, no. 3. 2009, pp. 41-44

[16] W. Kruskal and W. A. Walis, "Use of ranks in one-criterion variance analysis," Journal of the American Statistical Association, vol. 47, no. 260, pp. 583-62, 1952.

[17] S. Manikandan, "Measures of central tendency: Median and mode," Journal of Pharmacology and Pharmacotherapeutics, vol 2, no. 3, pp. 214-5, 2011

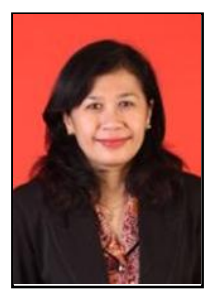

Nani Grace Berliana was born in Jakarta on October 24th, 1966. She first earned a bachelor's degree, majoring in mathematics at University of Indonesia Indonesia, in 1985. Second, she got a master degree on women studies at University of Indonesia in 1998.

She has worked for more than 20 years at Research Center for Development of Science and Technology Indonesian Institute of Sciences.

She was a head of Sub Division of Research Cooperation on 2000 until 2002; a head of sub-field of measurement and science and technology parameters on 2002 until 2010; The head of information systems and management of science and technology on 2011 until 2014 and the head of research and dissemination research division on 2014 until 2017. Since 2002 to date, she is a researcher in business R \& D and innovation, conducting measurement or R \& D and innovation. During the last four years doing research on the modeling of Science and Technology Human Resource.

Dra. Nani Grace Simamora, M. Hum has some scientific publications include Indonesian S\&T Indicators, Jakarta, LIPI Press, 2015; The Atlas of Islamic World Science and Innovation country Case Study Indonesia, Turki, OIC, 2014. Science and Technology in Indonesia-in Brief, Jakarta, Pappiptek, 2014. Study on the Status Science \& Technology Development in Indonesia, 2012. PAPPIPTEK-LIPI; Study on Implementation and Utilization of Mini / Micro Hydro Power Plants (PLTMH) for Increasing Productive Enterprises of Rural Communities, LIPI Press, 2010.

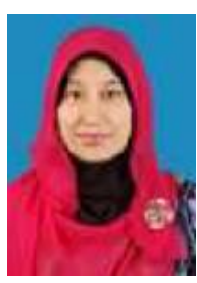

Indri J. Asmara was born in Medan Indonesia, on January 4th, 1981. She received her bachelor degree Indonesia, Jakarta, Indonesia.

She is a researcher in Center for S\&T Development Studies at Indonesian Institute of Sciences in Jakarta, Indonesia. The field of study is S\&T management and S\&T Policy.

She has several publication such as (1) "Technological capability upgrading and entrepreneurship: Case study of selected indonesian fish processing companies," STIPM, vol. 1 no.1, 2016. (2) "Technological convergence in Indonesian firms: Cases of biobased chemical product innovation," ASIAN Journal of Technology Innovation, 2015. (3) "Linking the supply on demand of Indonesia human resource in science and technology on the Black Swan phenomenon perspective," in Proc. ACEID2017 Proceeding. The past two years she has been done research about Human Resource that devoted on S\&T in Indonesia.

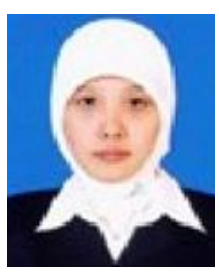

Elmi Achelia was born in Jakarta on January 27th, 1984. She earns her bachelor degree in computer science from IPB in 2005 and the master degree in information technology from University of Indonesia in 2012. Elmi is a researcher in Center of Science and Technology Development Studies, Indonesia Institute of Science (LIPI), joined with LIPI since 2006. She currently focuses in science and technology policy research, specifically in forecasting science and technology resources using system dynamics method. Also she is interested in research at field of computer science and information technology, as well as her previous research field in data mining and big data visualization. Her latest article in International Journal of Social Science and Humanity vol. 7, no. 6, pp. 494-500 titled "The Impact of Education on National HRST Performance," published in 2017. 